\title{
Hepatic encephalopathy in chronic liver disease; predisposing factors in a developing country
}

\author{
Fakhar Ali Qazi Arisar1, Shameem Behram Khan², Anam Umar² \\ ${ }^{1}$ Department of Medicine, Section of Gastroenterology, Aga Khan University Hospital, Karachi, Sindh, Pakistan, ${ }^{2}$ Department of Medicine, \\ Ward-5, Jinnah Post Graduate Medical Centre, Karachi, Sindh, Pakistan
}

\section{A B S T R A C T}

Objective: To find out the risk factors for developing Hepatic Encephalopathy in patients suffering from Chronic liver disease. Background: Hepatic encephalopathy (HE) is a neuropsychiatric disorder that is caused by liver damage. In its pathology, alterations in normal brain function are associated with an increase in blood ammonia, benzodiazepine like substances, products of neurotoxic fatty acids, and other gut derived toxins, which gain access to the brain as a result of liver dysfunction. Study Design: Hospital based descriptive, cross sectional study. Settings: Medical Unit 1, Ward- 5, Jinnah Post Graduate Medical Centre, Karachi. Duration: July 2013 to December 2013. Patients and Methods: About 150 patients admitted in medical unit 1 with a diagnosis of chronic liver disease in a state of hepatic encephalopathy were included in this study. Patients suffering from viral or bacterial encephalitis, stroke, brain tumor, Wernicke's encephalopathy were excluded from the study. Results and Observations: There were 96 (64\%) female and 54 (36\%) were male patients. Mean age of the patients was $52.45( \pm 12.271)$ years. $80(53.33 \%)$ patients were having constipation. Infection was found in 55 (36.66\%) cases. Upper Gl Bleed was present in $51(34 \%)$ patients. $44(29.33 \%)$ patients had moderate to severe electrolyte imbalance as the cause. Constipation alone was the cause in $11.33 \%$ of cases. More than one factor was found to be responsible in around $56 \%$ of patients while in $6.6 \%$ of cases none of these precipitating factors was isolated. Conclusion: Constipation is the commonest cause of hepatic encephalopathy followed by infection, upper GI bleed and electrolyte imbalance.

Key words: Hepatic encephalopathy, Precipitating factors, Cirrhosis of liver, Outcome

\section{INTRODUCTION}

Chronic liver disease is a worldwide major problem and alcohol is the leading cause of chronic liver disease in western societies, while hepatitis $\mathrm{B}$ and $\mathrm{C}$ viruses are the major in Pakistan. The prevalence of hepatitis B is over $10 \%$ in the Asia-pacific region where as the prevalence of chronic hepatitis $\mathrm{C}$ in the Asia-pacific region is variable between 4 to $12 \% .{ }^{1,2}$

It causes significant morbidity and mortality, mainly due to complications like hepatic encephalopathy, ascites, hepatorenal syndrome (HRS) and esophageal variceal hemorrhage $(\mathrm{EVH}){ }^{3}$ Hepatic encephalopathy (HE) is present in up to $70 \%$ of all patients with cirrhosis, including patients with abnormalities demonstrable only by psychometric testing, ${ }^{4,5}$ out of which about $30 \%$ patients of chronic liver disease die of hepatic encephalopathy. ${ }^{6,7}$

Hepatic encephalopathy describes a range of neuropsychiatric oddities that occur as a result of liver failure. The most primitive known paper to date on HE is by Giovanni Battista Morgagni in eighteenth century. Morgagni's book of medicine reported the case of a man with liver cirrhosis who had coma and subsequently died, whose gross brain examination did not show any alteration (Morgagni 1765). ${ }^{8}$ Many ideas generated and struggles are made to find out the exact pathophysiology of H.E. The diversion of portal blood into the systemic circulation through Porto systemic collateral vessels is found to be an imperative requirement 
for the syndrome. It accompanies portal-systemic shunting of venous blood that occurs either spontaneously, due to cirrhosis, or non-cirrhotic portal hypertension, or surgically following porto-caval anastomosis surgery or trans-jugular intra-hepatic porto-systemic shunt (TIPS) aimed at relieving portal hypertension. ${ }^{9}$

A relationship between portal-systemic shunting of blood and behavioral alterations, including coma, was clearly proven in porto-caval shunted dogs (i.e., submitted to Eck fistula) by Hahn et al. (1893) ${ }^{10}$ who demonstrated that meat-rich meals could cause 'encephalitis'.

Many studies also emphasize the role of neurotoxic agents in H.E. Van Caulet in $1932^{11}$ declared that Ammonia is the principal neurotoxin in instigating coma and disturbed brain function in patients of cirrhosis, the same was then proven by Sthal in $1936 .{ }^{12}$ Although many critic focused strictly on the involvement of neurotoxins and it remained controversial for a long period of time but now it is widely accepted that they have a certain role in the pathogenesis of H.E and among them ammonia is the toxin of interest. Ammonia formed by the colonic bacteria is carried to the liver via portal vein after absorption, where it is incorporated in the urea cycle for detoxification. Other gut-derived toxins have also been proposed e.g. benzodiazepine like substances, products of colonic bacterial metabolism such as neurotoxic short and medium chain fatty acids, phenols and mercaptans and manganese. Ammonia and the other substances gain access to the systemic circulation as a result of decreased hepatic function or porto-systemic shunts and harmfully disturbs brain function and theaters a role in the pathogenesis of H. E. In the brain these compounds produce alterations of neurotransmission that affect cognizance and behavior. Abnormalities in glutamatergic, serotoninergic, gaminobutyric acid-ergic (GABA-ergic) and catecholamine pathways have been described in experimental hepatic encephalopathy. The role of ammonia in hepatic encephalopathy is supported by the finding of high arterial ammonia level. The permeability of blood-brain barrier for ammonia is increased in patients with hepatic encephalopathy. Furthermore, ammonia after entering into the astrocytes, is metabolized and leads to changes in neurotransmission and hence alters the cellular functions. Manganese is deposited in basal ganglia and induces extra pyramidal symptomatology. It's also been proposed that an alteration in the ratio of branch chain amino acids and aliphatic amino acids can also predisposes to hepatic encephalopathy. ${ }^{13}$

\section{PATIENTS AND PROCEDURES}

\section{Study design and setting}

It was a hospital based descriptive, cross sectional study, carried out at department of medicine, ward 5,
Jinnah Postgraduate Medical Centre, Karachi, from July 2013 to December 2013. 150 consecutive patients of Chronic Liver Disease diagnosed previously or newly diagnosed after admission, between the ages of 14 to 83 years, presenting with encephalopathy were enrolled in the study.

\section{Data collection}

A Performa was structured and check list was used for data collection. Detailed history was obtained with special consideration to fever, GI bleed, Burning micturition, Diarrhea, vomiting, constipation, abdominal pain and distension, jaundice, diet and drugs like sedatives, diuretics and cough syrups. Patients were examined with special attention to fever, anemia, jaundice, palmar erythema, spider nevi, gynaecomastia, asterixis, dehydration, edema, splenomegaly and ascites. Relevant hematological, biochemical and radiological investigations were ordered including complete blood count, urea, creatinine and electrolytes, liver function tests, coagulation profile, serum proteins, serum albumin and globulin ratio, $\mathrm{HBsAg}$, Anti HCV Antibody, urine D/R, ascitic fluid D/R, serum ammonia, chest X-Ray, ultrasound abdomen, CT Brain and upper GI endoscopy. All patients underwent standard management during their hospital stay which included use of lactulose, metronidazole, 3rd generation cephalosporin, proton pump inhibitor, and vitamin $\mathrm{K}$ and FFP in patient with deranged coagulation profile or GI bleed. Ryle's tube for feeding purposes was placed in patients with hepatic encephalopathy grade $>2$. Outcomes assessed were the discharge or death during admission period.

\section{Inclusion criteria}

Cirrhosis was diagnosed on the basis of clinical signs \& symptoms, laboratory findings (deranged coagulation profile and reversal of albumin/globulin ratio) and ultrasound findings (size and echogenicity of liver, portal vein diameter, splenomegaly), and patients were categorized according to Child Pugh classification (Table 1). Diagnosis of hepatic encephalopathy was made on the basis of history, physical examination and number connection test, and was graded from I to IV according to the West Haven criteria (Table 2).

\section{Exclusion criteria}

Patients suffering from acute liver failure, non cirrhotic portal hypertension, intracranial lesions such as subdural

\begin{tabular}{|c|c|c|c|}
\hline & 1 & 2 & 3 \\
\hline Bilirubin (mg/dl) & $<2$ & $2-3$ & $>3$ \\
\hline Serum Albumin (g/dl) & $>3.5$ & $2.8-3.5$ & $<2.8$ \\
\hline Grade of Encephalopathy & None & Mild & Moderate to severe \\
\hline Grade of Ascites & None & Mild & Moderate to severe \\
\hline INR & $<1.2$ & $1.2-1.7$ & $>1.7$ \\
\hline
\end{tabular}


hematoma, cerebral infarction or bleed, meningitis, encephalitis, brain abscess, hypoxia, hypercarbia, ketoacidosis, neuropsychiatric disorders or post-epileptic confusion were excluded from the study.

\section{Operational definitions}

Constipation was defined as failure to pass stool in 48 hours, infection as presence of fever, raised leukocyte count, significant pyuria (at greater than or equal to 10 leucocytes $/ \mathrm{mm} 3),>500$ TLC or $>250$ neutrophils in ascitic $\mathrm{D} / \mathrm{R}$, electrolyte imbalance as high or low level of serum sodium or serum potassium as per the reference levels, upper gastrointestinal bleed as history of hematemesis or melena, dehydration as presence of dry tongue and loss of skin turgor, high protein diet as recent unrestricted high intake of proteins consumed in any form, renal impairment as creatinine of $>2$.

\section{Data analysis}

Statistical analysis was done using SPSS version 19 and the results were obtained in the terms of frequencies and percentages for descriptive analysis. Chi-Square and student $\mathrm{t}$ tests were used to analyze the numerical data and $\mathrm{p}$ value of $<0.05$ was considered statistically significant.

\section{RESULTS}

A total number of one hundred and fifty $(\mathrm{n}=150)$ adults diagnosed cases of chronic liver disease who presented with hepatic encephalopathy irrespective of cause were included, out of them ninety six $(\mathrm{n}=96$, $64 \%)$ were females and fifty four $(\mathrm{n}=54,36 \%)$ were males. Majority ( $\mathrm{n}=106,70 \%$ ) of the patients in our study belong from middle age group (i.e., 40-60 years of age), with mean age of 52.45 ( \pm 12.271$)$ years. The age and gender distribution of the patients is shown in Figure $1 \& 2$.

\begin{tabular}{ll} 
Table 2: West haven criteria \\
\hline Grade 1 & Mild confusion \\
& Trivial lack of awareness \\
& Euphoria or anxiety \\
& Shortened attention span \\
& Impaired performance of addition \\
& Drowsiness \\
& Lethargy or apathy \\
Grade 2 & Minimal disorientation for time or place \\
& Subtle personality change \\
& Inappropriate behavior \\
& Impaired performance of subtraction \\
& Somnolence but arousable \\
& Marked confusion \\
Grade 3 & Coma disorientation \\
& (unresponsive to verbal or noxious stimuli) \\
\hline
\end{tabular}

The most common cause of chronic liver disease was found to be HCV in our patients. Frequency of viral hepatitis as a cause of chronic liver disease is mentioned in Figure 3.

Out of 150 admitted patients, 107 (71.3\%) were discharged, while $43(28.7 \%)$ passed away. The frequency of grade of hepatic encephalopathy in our patients is shown in Figure 4.

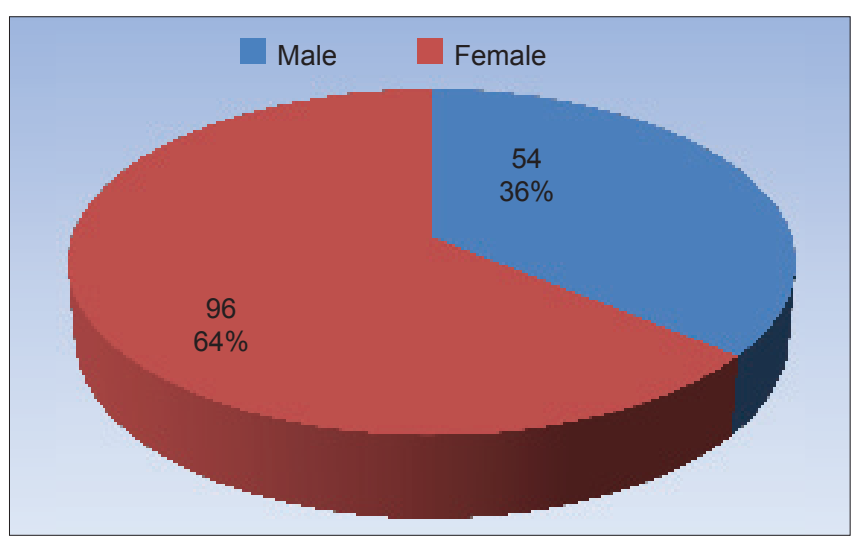

Figure 1: Gender distribution of patients included in the study

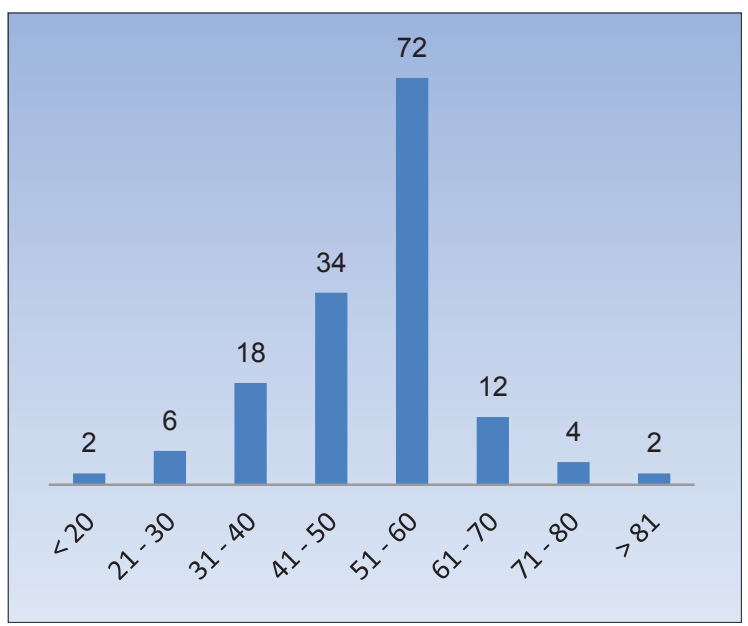

Figure 2: Age frequency of the patients enrolled in the study

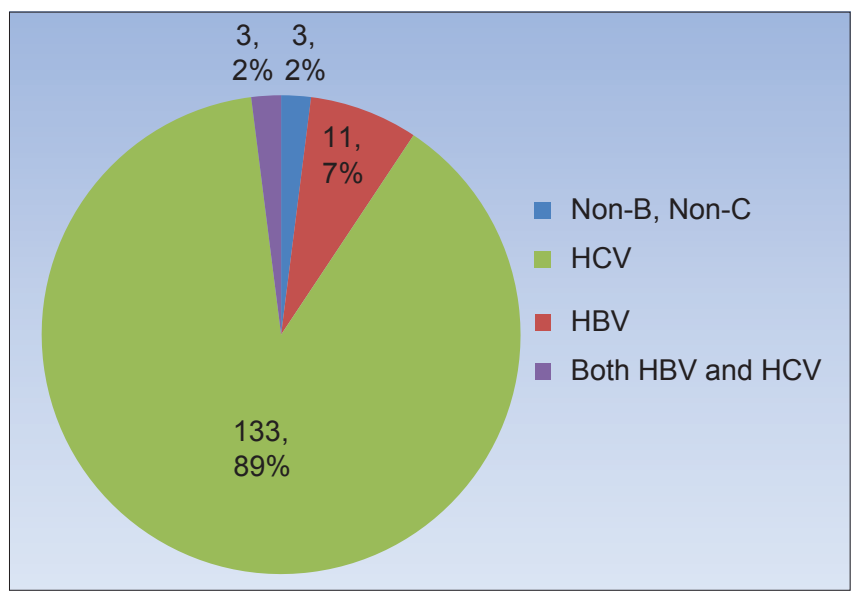

Figure 3: Frequency of vital hepatitis as a cause of chronic liver disease 
Sign \& symptoms (in the decreasing order of frequency) and the laboratory parameters of our patients are mentioned in the Figure 5 and Table 3.

TLC count was low in $13(8.66 \%)$, normal in $94(62.66 \%)$ and high in $43(28.66 \%)$ of our patients. Urea was deranged in $78(52 \%)$, while creatinine was high in $20(13.33 \%)$ of the cases. Hypoalbuminema was recorded in 118 (78.66\%), while deranged coagulation profile was found in $85(56.66 \%)$ of subjects. Fifty one (51) patients in our study presented with GI Bleed comprising of $34 \%$ of total cases.

Out of 150 patients, 07 (4.6\%) had hypernatremia while $62(41.33 \%)$ had normal sodium level. Hyponatremia was present in $81(54 \%)$ patients. Of those having hyponatremia, 51 patients fall in the category of mild,

\begin{tabular}{|c|c|c|c|c|}
\hline & Minimum & Maximum & Mean & $\begin{array}{c}\text { Std. } \\
\text { deviation }\end{array}$ \\
\hline Hemoglobin (mg/dl) & 1.7 & 13.2 & 8.417 & 2.1582 \\
\hline TLC $\left(\times 10^{9} / \mathrm{L}\right)$ & 1.8 & 33.0 & 9.291 & 5.9084 \\
\hline Neutrophils ( $\%$ of WBC) & 5 & 94 & 75.04 & 18.562 \\
\hline Platelets & 15 & 388 & 96.19 & 63.906 \\
\hline RBS (mg/dl) & 61 & 591 & 149.63 & 88.079 \\
\hline Urea (mg/dl) & 15 & 201 & 61.56 & 46.069 \\
\hline Creatinine $(\mathrm{mg} / \mathrm{dl})$ & 0.10 & 5.20 & 1.3939 & 0.97563 \\
\hline Serum Sodium (meq/l) & 83.0 & 153.0 & 131.840 & 10.1431 \\
\hline Serum Potassium (meq/l) & 1.70 & 5.94 & 3.8703 & 0.96595 \\
\hline Serum Chloride (meq/l) & 81.0 & 127.8 & 102.518 & 9.1711 \\
\hline Total Bilirubin (mg/dl) & 0.60 & 26.00 & 4.3302 & 4.93379 \\
\hline $\operatorname{ALT}(\mathrm{u} / \mathrm{l})$ & 12 & 113 & 37.34 & 20.899 \\
\hline AST $(u / l)$ & 22 & 304 & 80.02 & 60.401 \\
\hline Serum Albumin (mg/dl) & 1.6 & 33.0 & 3.574 & 4.0016 \\
\hline $\mathrm{A} / \mathrm{G}$ ratio & 0.4 & 1.2 & 0.816 & 0.1536 \\
\hline PT (sec) & 13.0 & 38.6 & 20.171 & 6.5844 \\
\hline INR & 1.00 & 4.10 & 1.5506 & 0.63901 \\
\hline Serum Ammonia ( $\mu \mathrm{g} / \mathrm{dl})$ & 31 & 388 & 191.29 & 94.566 \\
\hline Liver span $(\mathrm{cm})$ & 7.3 & 14.6 & 11.115 & 1.9717 \\
\hline Portal vein diameter & 0.7 & 2.0 & 1.19 & 0.3210 \\
\hline Spleen size & 8.8 & 18.9 & 13.43 & 2.1089 \\
\hline
\end{tabular}

23 in moderate and 7 had severely low serum sodium. Similarly, out of total 150 patients $07(4.6 \%)$ had hyperkalemia while $92(61.33 \%)$ had normal potassium level. Hypokaelmia was present in $51(34 \%)$ patients. Of those having hypokalemia, 42 patients fall in the category of mild, and 9 had moderately low serum potassium. Frequency of infections and electrolyte imbalances is mentioned in the Table 4.

Eighty $(53.33 \%)$ patients were having constipation. Infection was found in $55(36.66 \%)$ cases. Upper GI Bleed was present in 51 (34\%) patients. $44(29.33 \%)$ patients had moderate to severe electrolyte imbalance as the cause. Constipation alone was the cause in $11.33 \%$ of cases. More than one factor was found to be responsible in around $56 \%$ of patients while in $6.6 \%$ of cases none of these precipitating factors was isolated.

Grade of hepatic encephalopathy in our patients was directly related with the number of predisposing factors as shown in Table 5.

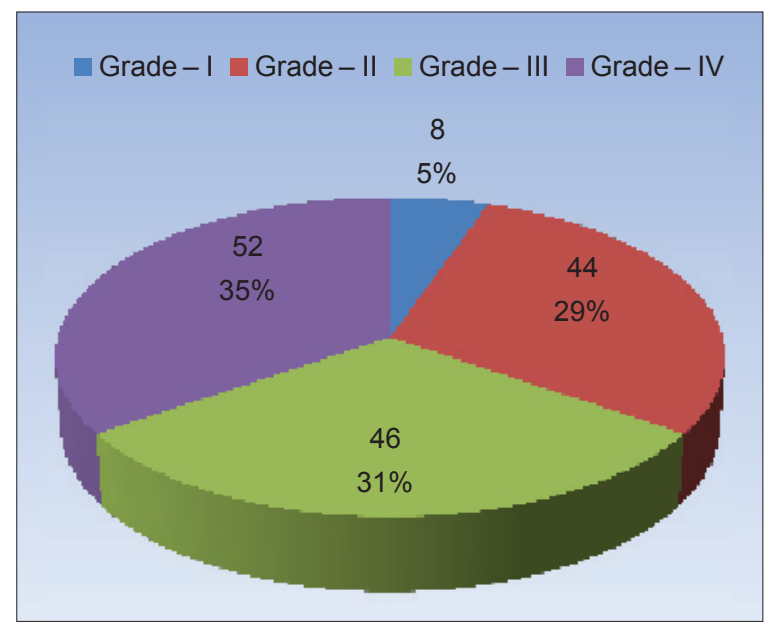

Figure 4: Classification of patients according to the grades of encephalopathy

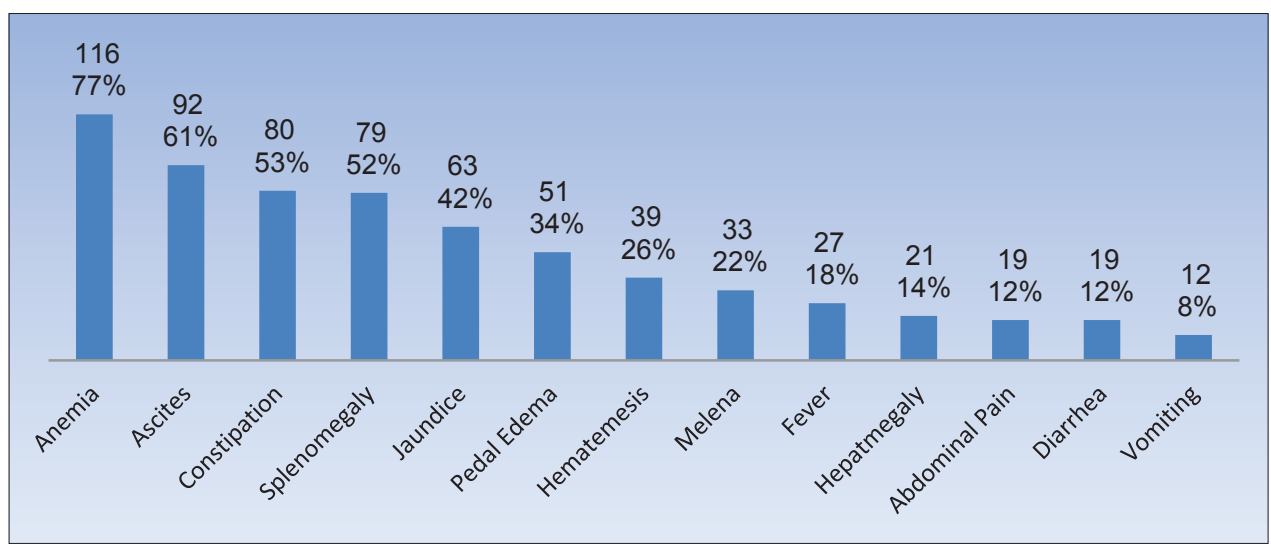

Figure 5: Sign and symptoms of the patients included in the study 


\begin{tabular}{lcc} 
Table 4: Frequency of infection & \\
\hline & Frequency & Percentage \\
\hline Absent & 95 & 63.33 \\
Present & 55 & 36.66 \\
Malaria & 2 & 3.63 \\
SBP & 5 & 9.09 \\
Gastroenteritis & 6 & 10.9 \\
Others (UTI, RTI) & 42 & 76.36 \\
\hline
\end{tabular}

\begin{tabular}{|c|c|c|c|c|c|}
\hline \multirow[t]{2}{*}{ Cause } & \multicolumn{4}{|c|}{$\begin{array}{l}\text { Grade of hepatic } \\
\text { encephalopathy }\end{array}$} & \multirow[t]{2}{*}{ Total } \\
\hline & I & II & III & IV & \\
\hline None & 0 & 3 & 2 & 5 & 10 \\
\hline \multicolumn{6}{|l|}{ Single cause } \\
\hline Bleed & 0 & 0 & 3 & 3 & 6 \\
\hline Infection & 0 & 3 & 3 & 4 & 10 \\
\hline Constipation & 0 & 7 & 2 & 8 & 17 \\
\hline Electrolyte Imbalance & 0 & 2 & 5 & 16 & 23 \\
\hline More than 1 cause & 8 & 29 & 31 & 16 & 84 \\
\hline Total & 8 & 44 & 46 & 52 & 150 \\
\hline
\end{tabular}

\begin{tabular}{|c|c|c|c|c|}
\hline & \multicolumn{3}{|c|}{ Child-pugh class } & \multirow[t]{2}{*}{ Total } \\
\hline & A & B & C & \\
\hline \multicolumn{5}{|l|}{ Outcome } \\
\hline Discharge & 9 & 53 & 45 & 107 \\
\hline Expire & 0 & 11 & 32 & 43 \\
\hline Total & 9 & 64 & 77 & 150 \\
\hline
\end{tabular}

To assess the severity of liver disease in our patients, Child-Pugh and MELD scoring systems were applied. The mean MELD score of our patients was 17.2 while mean Child-Pugh Score was 9.65.

Chi-square test was used to determine the relation of child's class with mortality rate, and it was found that mortality rate was significantly high in child class $C$ patients as shown in Tables 6.

The grade of hepatic encephalopathy at the time of presentation was directly related with the outcome ( $\mathrm{P}$ value $<0.001)$ and is summarized in the Figure 6.

\section{DISCUSSION}

A clearly defined precipitating factor is usually identified in most patients with hepatic encephalopathy and the reversal or control of these factors is a key step in the management. The results of our study showed that 133 patients $(88.66 \%)$ were suffering from Hepatitis C, and 11 patients (7.33\%)

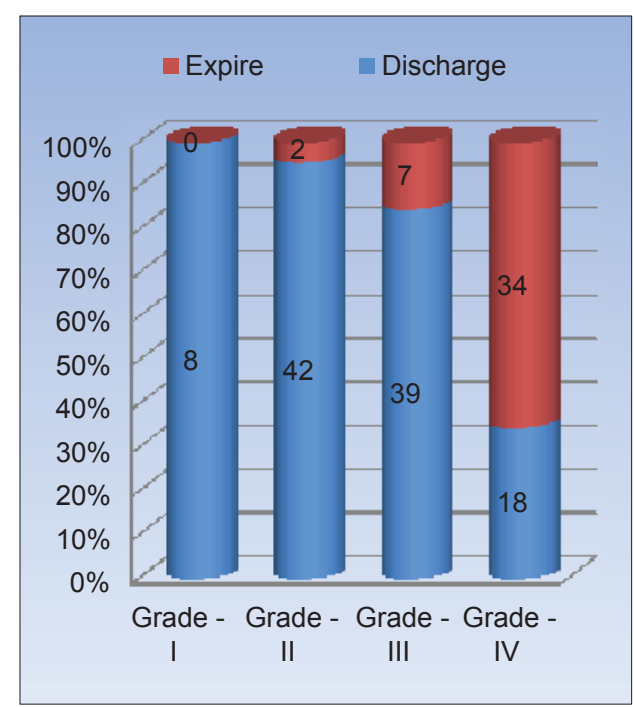

Figure 6: Grade of hepatic encephalopathy relating with outome in terms of mortality

were of hepatitis B. Since it was a consecutive type of sampling, avoiding selection bias, so our findings are in conformation with other studies, which also emphasize the fact that HCV is a rapidly growing problem and has already overtaken HBV in the etiogenesis of hepatic encephalopathy in Pakistan. ${ }^{14,15}$ A review article by Jafri described a rise in frequency of HCV as a cause of CLD in Pakistan from $16.67 \%$ in early nineties to $51-86 \%$ over a period of time. ${ }^{16}$

Constipation was the commonest factor responsible for $53 \%$ cases of Hepatic encephalopathy in our patients, which is close to earlier published studies (as summarized in Table 7), ${ }^{17-20}$ however contradictory with some of national and international reports. ${ }^{21-28}$ High frequency of constipation in our population was perhaps due to the fact that people of our country were probably less aware of the importance of constipation, precipitating hepatic encephalopathy. ${ }^{19}$ Other factors responsible for prevalence of constipation among our setup include dietary restriction, poverty, lack of use or inappropriate dosing of lactulose due to financial constrains, and lack of education regarding role of diet in chornic liver disease. ${ }^{18,20}$ Also most of the patient in our study belong middle age group, and that increasing age effects the bowel habits, it may partly be the reason of high prevalence of constipation in our study. ${ }^{21,22}$ Liver and brain biopsies were not taken in our study.

Proper guidance about a healthy diet which consists of plenty of fresh fruits and vegetable, foods high in fiber content (including whole-meal bread, whole-wheat cereal and some raw bran in cereal or yoghurt), foods that are high in Omega-3 fatty acids and adequate fluid intake to avoid dehydration should be provided to all the patients of Chronic liver disease. Exercise is an integral feature of 


\begin{tabular}{|c|c|c|c|c|c|c|c|c|c|c|c|c|c|c|}
\hline Author/Place/Year & $\mathbf{n}$ & Constipation & INF & SBP & Diarrhea & Malaria & $\begin{array}{c}\text { Other } \\
\text { infections } \\
\text { (RTI, UTI) }\end{array}$ & $\begin{array}{c}\text { GI } \\
\text { Bleed }\end{array}$ & $\begin{array}{l}\text { Low } \\
\mathrm{Na}+\end{array}$ & $\begin{array}{c}\text { Low } \\
\mathrm{K}+\end{array}$ & Azotemia & None & 1 cause & $>1$ cause \\
\hline $\begin{array}{l}\text { Present Study/JPMC } \\
\text { Karachi/2013 }\end{array}$ & 150 & 53 & 36.66 & 3.33 & 12 & 1.33 & 28 & 34 & 54 & 34 & 52 & 6.66 & 37 & 56 \\
\hline Mahboob $^{6}$ & - & 19 & 47 & - & 5 & - & - & 30 & - & - & - & - & - & - \\
\hline $\begin{array}{l}\text { Bikha Ram Devrajani13/ } \\
\text { LUMHS Jamshoro/2007 }\end{array}$ & 87 & 49 & 67 & - & - & - & - & 45 & - & 33 & - & 6 & - & - \\
\hline $\begin{array}{l}\text { Akhtar Ali Baloch }{ }^{17 /} \\
\text { CHK/2009 }\end{array}$ & 190 & 49.5 & 38.9 & - & - & - & - & 32.6 & - & - & - & - & - & - \\
\hline $\begin{array}{l}\text { Naila Masood }{ }^{18} / \text { LUMHS } \\
\text { Jamshoro/2009 }\end{array}$ & 90 & 31.1 & 27.8 & - & - & - & - & 10 & 13.3 & 37.8 & - & 13.3 & - & - \\
\hline $\begin{array}{l}\text { Hameed Ahmed }{ }^{19 /} \\
\text { Lady Reading Hosp. } \\
\text { Peshawar }\end{array}$ & 50 & 52 & - & - & 22 & - & - & 56 & 28 & 68 & - & - & - & - \\
\hline $\begin{array}{l}\text { Saira Afzal }{ }^{20} / K E M U \\
\text { Lahore/2005-06 }\end{array}$ & 50 & 60 & 10 & - & - & - & - & 18 & - & - & - & - & - & - \\
\hline $\begin{array}{l}\text { Col. Dr. Manzar } \\
\text { Zakaria }{ }^{21 / C M H} \\
\text { Lahore/2007 }\end{array}$ & 80 & 6.3 & 27.5 & - & - & - & - & 56.3 & - & - & - & 8.8 & - & - \\
\hline $\begin{array}{l}\text { Khalid Mumtaz }{ }^{22} / \text { AKUH } \\
\text { Karachi/2005-07 }\end{array}$ & 404 & 18.3 & - & 20.5 & - & - & 15.3 & 13.6 & 3 & 6.4 & - & - & 53 & 35 \\
\hline $\begin{array}{l}\text { Dileep k. Rohra²3/ } \\
\text { CHK/2006 }\end{array}$ & 256 & 12.1 & - & 10.9 & - & - & 9 & 15.2 & - & - & - & 50.8 & - & - \\
\hline $\begin{array}{l}\text { Intekhab Alam }{ }^{24} / \text { Lady } \\
\text { Reading Hospital } \\
\text { Peshawar/2005 }\end{array}$ & 50 & 32 & 24 & - & 40 & - & - & 22 & 38 & 18 & - & - & - & - \\
\hline $\begin{array}{l}\text { Imran Ahmed }{ }^{25} / \mathrm{CMH} \\
\text { Okara/2005 }\end{array}$ & 43 & 20.9 & 7 & - & - & - & - & 37.2 & - & 14 & - & 9.3 & - & - \\
\hline Souheil'26 & 100 & 3 & 3 & - & - & - & - & 18 & - & 11 & - & - & - & - \\
\hline Faloon \& Evans ${ }^{27}$ & 39 & 6 & - & - & - & - & - & 33 & - & 18 & 33 & 3 & - & - \\
\hline Conn \& Liebertha ${ }^{28}$ & 1000 & 3 & 4 & - & - & - & - & 18 & - & 9 & 30 & 2 & - & - \\
\hline $\begin{array}{l}\text { M. Tariq }{ }^{32} / \text { Khyber } \\
\text { Teaching Hospital } \\
\text { Peshawar/2006 }\end{array}$ & 200 & 30 & 30 & 8 & 3 & - & 22 & 29 & 1.5 & 4.5 & - & - & - & - \\
\hline
\end{tabular}

bowel management programs, and a lack of physical activity is a factor in the development of constipation in some people. Its effectiveness as an intervention to prevent or treat constipation, however, has yet to be demonstrated. ${ }^{29}$

Lactulose is a commonly prescribed agent to relieve constipation in patients with chronic liver disease. It has an added advantage as a non-absorbable disaccharide inhibiting intestinal ammonia production by number of mechanisms. ${ }^{30,31}$

Infections like SBP, urinary tract infection and lower respiratory tract infection were the $2^{\text {nd }}$ most common factor present in $37 \%$ of cases corresponds to the study of Mohammad Tariq (2006). ${ }^{32}$ In West however the infection as a cause of hepatic encephalopathy is not very common, possibly due to more awareness and better nutrition status in their patients.

GI bleed was the third most important factor and was found in 34\% of patients in our study, which is similar to $30 \%$ found in Mehboob F (2003), ${ }^{6}$ although lower than that reported by zakaria. ${ }^{21}$

Electrolyte imbalance was found in $29 \%$ patients. Among electrolytes, hyponatremia was much more common than hypokalemia in our patients which was consistent with the findings of Alam, ${ }^{24}$ but contradicts with those ofAhmed. ${ }^{19}$ Electrolyte imbalances also correlate with the severity of the liver disease. ${ }^{33}$

In our study, sedatives and Tranquilizers were not in use of any patient, and the history taken from the attendants and patients themselves were not suggestive of any self prescription of such drugs. In this study the majority of patients are in age group of 50 to 60 and the female were dominant, which is contradictory with the findings observed in a retrospective study, of hepatic encephalopathy in Saudi Arabia $^{34}$ and in civil hospital Hyderabad. ${ }^{13}$

When grading of encephalopathy is considered, in grade 3 and 4 electrolyte imbalance is the single most common precipitating factor involved.

The mortality rate of hepatic encephalopathy is high as shown by the study of Sargent et al ${ }^{35}$ whereas, in our study the mortality was $29 \%$ and the majority were, Class C, Child- Pugh classification. Patients with chronic HE are known to have better long term (5 years) survival than those who develop HE acutely (100\% vs. $70 \%$ survival). ${ }^{36}$ But this 
survival can be improved as appropriate treatment and care can cause complete recovery especially if encephalopathy is elicited by a rescindable cause. So there is a definite need for health education in patients regarding the risk of $\mathrm{HE}$ and its precipitating factors, as lack of awareness about this life threatening complication of CLD is itself a cause of acquiring hepatic encephalopathy. So a constant need and effort to obviate them by all possible measures is necessary. Proper dietary advice must be an important part of all counseling practices to chronic liver disease patients.

\section{CONCLUSION}

Constipation is the commonest cause of hepatic encephalopathy followed by infection, upper GI bleed and electrolyte imbalance. Control of constipation is very imperative in the avoidance of hepatic encephalopathy in our setup. The leading cause of constipation is a poor diet - poor choice of foods, or irregular eating. Patient counseling is a key competency element in its prevention. In most cases, simple changes in diet and lifestyle as described above can help relieve symptoms and manage constipation, and so very effectively prevent the development of this life threatening complication of cirrhosis.

\section{ACKNOWLEDGMENTS}

Dr. Sham Kumar, Dr. Tariq Aziz, Dr. Rasheed Durrani, Dr. Tahir Ansari, Dr. Rukhsana Sattar, Dr. Jamal Ara.

\section{REFERENCES}

1. Almani SA, Memon AS, Memon Al, Shah I, Rahpoto $Q$, Solangi R. Cirrhosis of liver: Etiological factors, complications and prognosis. J Liaquat Uni Med Health Sci 2008; 7(2):61-66.

2. Chen DS. Public health measures to control hepatitis $B$ virus infection in the developing countries of the Asia-Pacific Region. J Gastroenterol Hepatol 2000; 15: E7-10.

3. Rahimi RS, Rockey DC. Complications and outcomes in chronic liver disease. Curr Opin Gastroenterol 2011; 27(3):204-209.

4. Gilberstadt SJ, Gilberstadt H, Zieve L, Buegel B, Collier RO Jr, Mc-Clain CJ. Psychomotor performance defects in cirrhotic patients without overt encephalopathy. Arch Intern Med 1980; 140:519-521.

5. Gitlin N, Lewis DC, Hinkley L. The diagnosis and prevalence of subclinical hepatic encephalopathy in apparently healthy, ambulant, non-shunted patients with cirrhosis. J Hepatol 1986; 3:75-82.

6. Mehboob F. Frequency of risk factors for hepatic encephalopathy in patients of chronic liver disease. Ann King Edward Med Coll 2003; 9:29-30

7. Alam. I, Razaullah, Haider I, Humayun M, Taqweem MA, Nisar M, Intikhab et al. Spectrum of precipitating factors for hepatic encephalopathy in liver disease. Pak J Med Res 2005; 44:96-100
8. Amodio P. The liver, the brain and nitrogen metabolism. Metab Brain Dis 2009; 24: 1-4

9. Mumtaz K, Ahmed US, Abid S, Baig N, Hamid S, Jafri W. Precipitating Factors and The Outcome of Hepatic Encephalopathy in Liver Cirrhosis.J Coll Physicians Surg Pak 2010; 20(8):514-518.

10. Hahn M, Massen O, Nencki M, Pavlov I (1893). Die Eck'schefistelzwischen der unterenhohlvene und der pfortader und ihrefolgen fur den organismus. Arch Exp Pathol Pharm 32:161-210

11. Van Caulert C, Deviller C, Halff M (1932). Troubles provoquesparl'ingestion de selsammoniacaux chez I'hommeatteint de cirrhose de Laennec. Comptes Rendus Soc Biol 111:739-740.

12. Sthal J (1936). Studies of the blood ammonia in liver disease. Ann Intern Med 58:1-24

13. Devrajani BR, Shah SZ, Devrajani T, Kumar D. Precipitating factors of hepatic encephalopathy at a tertiary care hospital Jamshoro, Hyderabad. J Pak Med Assoc 2009; 59(10):683-686.

14. Malik A, Butt SA, Tariq WZ. Hepatitis $C$ virus in perspective, where do we stand [editorial]. J Coll Physician Surg Pak 1996; 6: 136.

15. Alam I, Razaullah, Haider I, Humayun M, Taqweem A, NisarM.SpectrumofprecipitatingfactorsofHepaticEncephalopathy in liver cirrhosis. Pak J Med Res 2005; 44(2):96-100.

16. Jafri W, Subhan A. Hepatitis $C$ in Pakistan: magnitude, genotype, disease characteristics and therapeutic respons. Tropical Gastroenterology 2008; 29(4):194-201

17. Baloch AA, Shaikh NA, Lal H, Jakhrani N, Masroor M. Common precipitating factors of hepatic encephalopathy in patients of chronic liver disease at civil hospital Karachi. Med Channel 2010; 16(4):520-523.

18. Masood N, Rahopoto Q, Gouri A, Munir A. Precipitating factors of hepatic encephalopathy in patients with cirrhosis of liver. Med channel 2010; 16(3): 376-379

19. Ahmed H, Rehman MU, Saeedi MI, Shah D. Factors precipitating hepatic encephalopathy in cirrhosis of liver. J Postgrad Med Inst 2001; 15(1): 91-97

20. Afzal S, Ahmad M. Precipitating factors of hepatic coma. Ann King Edward Med Uni 2011; 17(3): 213-217

21. Zakaria M, Butt MA, Hussain SR, Rana GF. Hepatic encephalopathy; precipitating factors in patients with cirrhosis. Professional Med J 2008; 15(3): 375-379.

22. Mumtaz K, Ahmed US, Abid S, Baig N, Hamid S, Jafri W. Precipitating factors and the outcome of hepatic encephalopathy in liver cirrhosis. J Coll Physicians Surg Pak 2010; 20(8): 514518

23. Rohra DK, Jaipal, Khowaja AA, Mahmood K, Ahuja KL. Precipitating factors of hepatic encephalopathy in patients with chornic liver disease at civil hospital Karachi. J Coll Physicians Surg Pak 2008; 18(2): 130-131

24. Alam I, Razaullah, Haider I, Humayun M, Taqweem MA, Nisar M. Spectrum of precipitating factors of hepatic encephalopathy in liver cirrhosis. Pakistan J Med Res 2005; 44(2): 96-100

25. Ahmed I, Amin ZA, Ashraf HM. Determination of factors precipitating encephalopathy in patients with liver cirrhosis. Pak Armed Forces Med J Sep 2006; 56(3): 284-288

26. Souheil Abu-Assi, Vlaeevie ZR. Hepatic encephalo-pathy: metabolic consequences of the cirrhois are often reversible. Post graduate Med 2001;109:80.

27. Fallon WW, Evans GL. Precipitating factors in genesis of hepatic coma. N Y Stage J Med 1970; 70:2891-2896.

28. Conn HO, Leiberlhal MM. The hepatic coma syndrome and lactulose. Baltimore: Williams and Wilkins; 1980: P-106. 
29. RNAO. Prevention of Constipation in the Older Adult Population. Nursing Best Practice Guideline: Shaping the future of Nursing, revised March 2005.

30. Dhiman RK, Sawahney MS, Chawla YK, Das G, Ram S, Dilawari JB. Efficacy of Lactulose in cirrhotic patients with sub clinical hepatic encephalopathy. Digs Dis Sci 2000; 45:15491552.

31. Banares R, Carneros JA, Rincon D. New treatments of hepatic encephalopathy. Gastroenterol Hepatol 1998; 21:196-202.

32. Tariq M, lqbal S, Khan NU, Basari R. Precipitating factors of hepatic Encephalopathy. Rawal Med J 2009; 34(1):95-97.

33. Kuramitsu T, Komatsu M, Matsudaira N, Naganuma T,
Niizawa M, Zeniya A, et al. Portal systemic encephalopathy from a spontaneous gastrorenal shunt diagnosed by three dimensional computed tomography and treated effectively by percutaneous vascular embolization. Liver 1998; 18:208-212.

34. Al-Gindan YM. Hepatic encephalopathy in Saudi Arabia: retrospective analysis of 51 patients. Indian J Med Sci 1992; 46:69-74.

35. Sargent S, Fullwood D. The management of hepatic encephalopathy and cerebral oedema in acute liver failure. $\mathrm{Br} \mathrm{J}$ Neuroscience Nurs 2006; 2:448-453.

36. Sherlock S, Dooley J. Disease of the liver and biliary system. $11^{\text {th }}$ ed. London: Blackwell Science; 2002.

\section{Authors Contribution:}

FAQA - designed the study, collected and analyzed the data, drafted the manuscript, \& reviewed the manuscript; SBK - Contributed to the study design and collection of data; AU - Contributed in collection of data, writing of manuscript.

Source of Support: Nil. Conflict of Interest: None declared. 